[Agr. Biol. Chem., Vol. 32, No. 11, p. 1362 1370, 1968]

\title{
Synthesis and Properties of Isomeric Di- and Mono- Glucopyranosyl Hypoxanthines
}

\author{
(Synthesis in Nucleoside Antibiotics, V) \\ By Hajime Yamasaki* and Takeshi Hashizume \\ Department of Food Science and Technology, Kyoto University, Kyoto \\ Received June 6, 1968
}

\begin{abstract}
Four isomeric glucosyl hypoxanthines, bis-1,9-( $\beta$-D-glucopyranosyl) hypoxanthine (I), bis-1,7-( $\beta$-D-glucopyranosyl) hypoxanthine (II), 7- $\beta$-D-glucopyranosyl hypoxanthine (III) and 9- $\beta$-D-glucopyranosyl hypoxanthine (IV) were synthesized simultaneously by using the socalled Davoll-Lowy's method. Their synthetic procedures and structural evidences are presented.
\end{abstract}

In a recent communication, ${ }^{11}$ we have reported that when the bromomercury derivative of hypoxanthine was refluxed with acetobromoglucose in xylene two isomeric diglucosyl hypoxanthines are produced simultaneously (12.7\% and $12.3 \%$ ) besides two expected monoglucosides $(6.0 \%$ and $10.2 \%)$. The structures of the four isomeric glucosyl hypoxanthines were bis-1,9-( $\beta$-D-glucopyranosyl) hypoxanthine (I), its 1,7-position isomer (II), 7- $\beta$-D-glucopyranosyl hypoxanthine (III) and its 9-position isomer (IV) as identified with infra-red, NMR and ultraviolet absorption spectra and some other experimental results. ${ }^{11}$

In this paper the procedures of the above reactions are described in detail and some additional evidences in support of the $\mathrm{N}-1$ glucosides for compounds I and II are also discussed.

When compound I was treated with $1 \mathrm{~N}$ hydrochloric acid for $1.5 \mathrm{hr}$ at $100^{\circ} \mathrm{C}$, monoglucosyl hypoxanthine was obtained in a $50 \%$ yield, and it was determined as 1- $\beta$-D-glucopyranosyl

\footnotetext{
* Present address: Department of Biochemistry, Tottori University School of Medicine, Yonago.

1) T. Hashizume and H. Yamasaki, Tetrahedron Letters, 39, 3839 (1967).
}

hypoxanthine (V) spectrophotometrically. Compound II also gave 1- $\beta$-D-glucopyranosyl hypoxanthine (V) by the acid treatment." This result revealed that the glucosidic linkage at the $\mathrm{N}-1$ position is more resistant than at any of the nitrogen atoms in the imidazole ring against the acid hydrolysis and that the N-1 glucoside of hypoxanthine seemed to be 3glycosyl-6-hydroxypyrimidine. When 3- $\beta$-Dribofuranosyl uracil was treated with $1 \mathrm{~N}$ hydrochloric acid for $3 \mathrm{hr}$ at $100^{\circ} \mathrm{C}$, a $43 \%$ yield of uracil was obtained. ${ }^{2}$ But the N-9 glycosidic bond of purine nucleosides was completely hydrolyzed by $\mathrm{N}$-hydrochloric acid at $100^{\circ} \mathrm{C}$ for $1 \mathrm{hr}^{3 .}$ Moreover, one of the two anomeric protons of compound I $(\delta, 5.72$ and $6.08 \mathrm{ppm})$ and compound II $(\delta, 5.98$ and $6.02 \mathrm{ppm})$ on their NMR spectra gave almost the same chemical shift as the proton of compound $\mathrm{V}(\delta, 6.02 \mathrm{ppm})$ (Figs. 1, 2 and 3$)$.

The ring opening of a purine nucleoside having a substituent on one of the pyrimidine ring nitrogen atoms was observed by several

2) J.P. Scannell and F.W. Allen, J. Org. Chem., 25, 2143 (1960).

3) E. Vischer and E. Chargaff, J. Biol. Chem., 176, 715 (1948). 


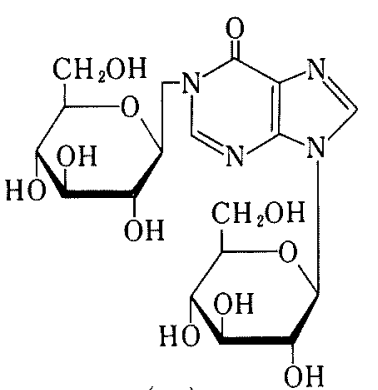

( I )

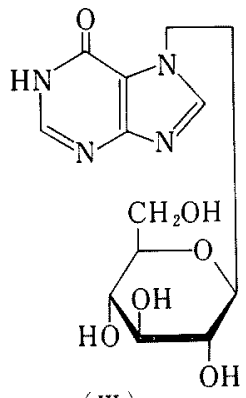

(III)

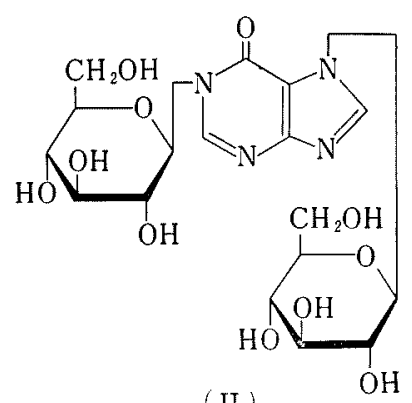

(II)

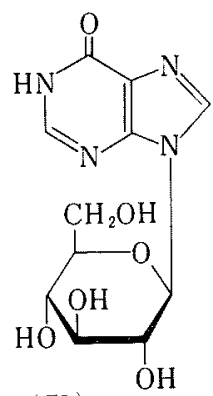

(IV)

CHART 1
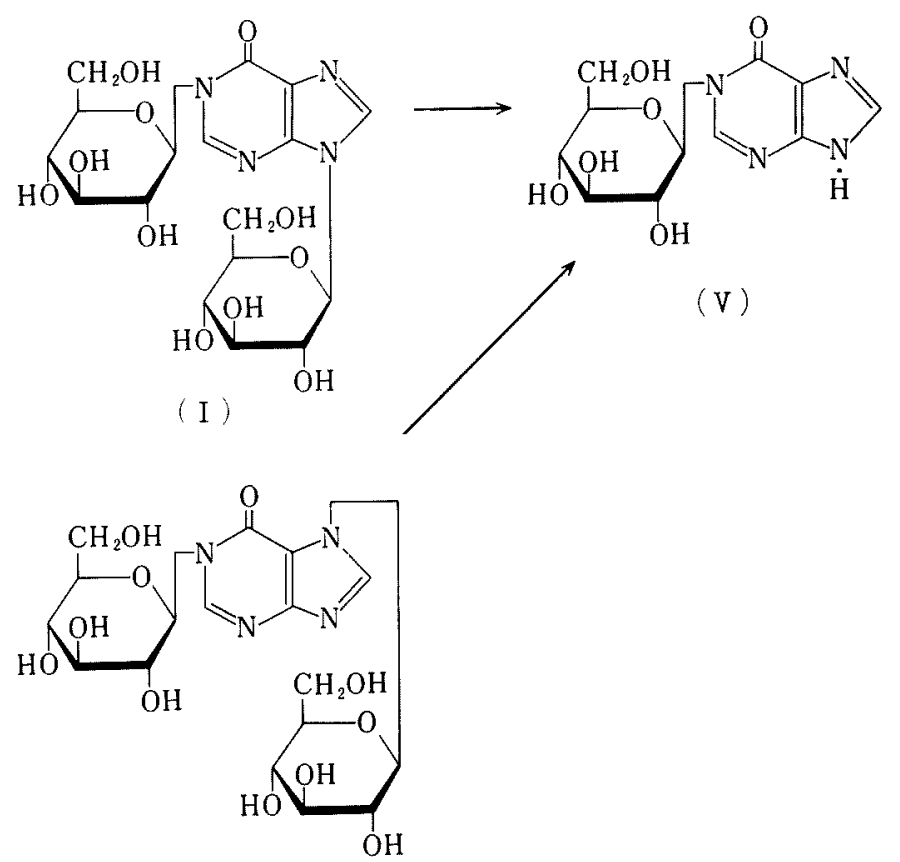

(II)

Chart 2 


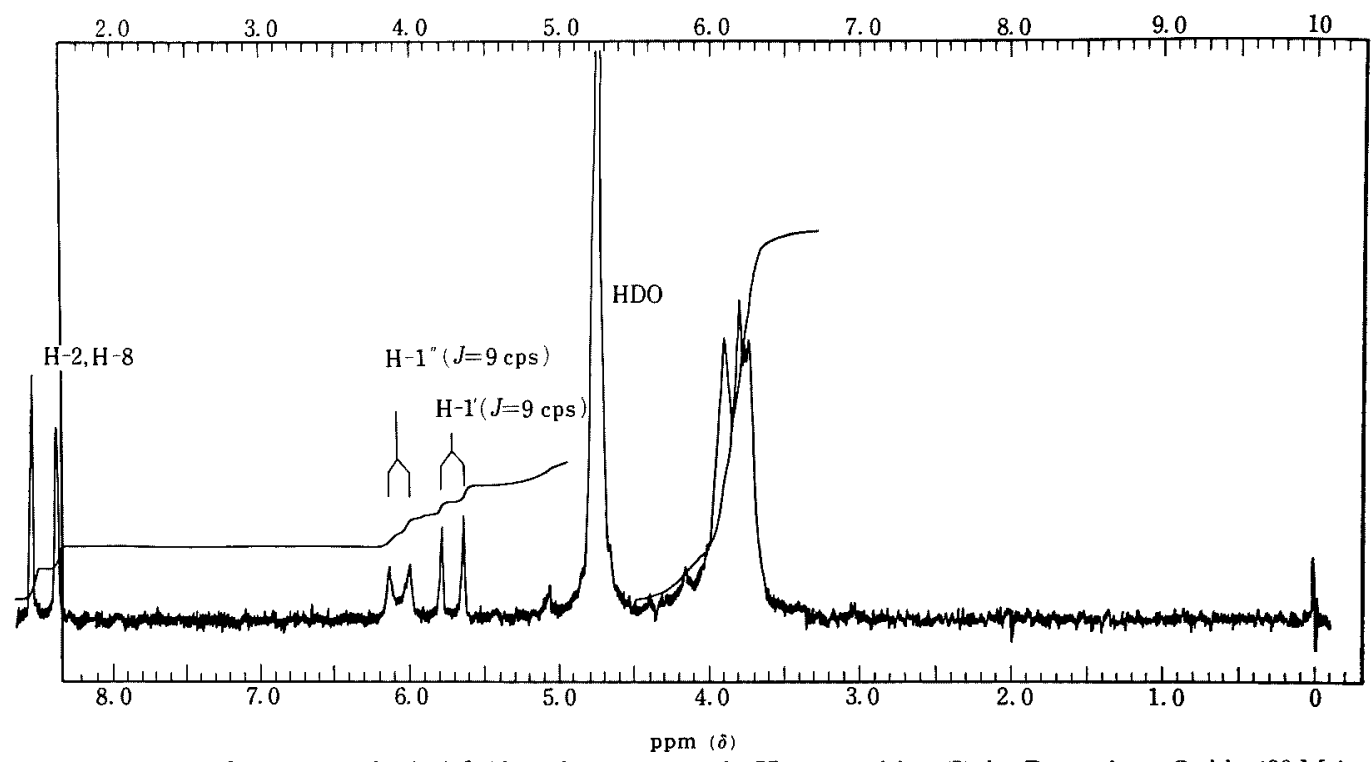

FIG. 1. NMR Spectrum of Bis-1,9-( $\beta$-D-glucopyranosyl) Hypoxanthine (I) in Deuterium Oxide (60 Mc).

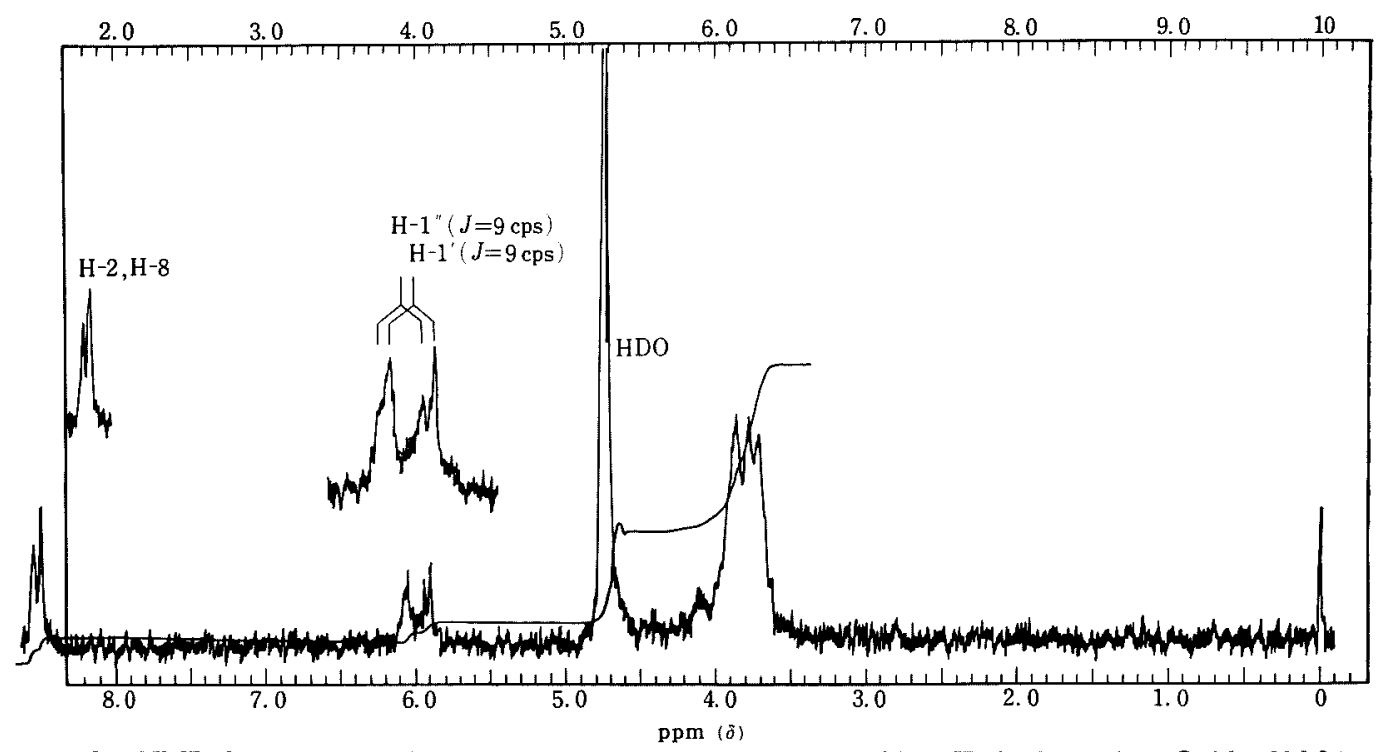

FIG. 2. NMR Spectrum of Bis-1,7-( $\beta$-D-Glucopyranosyl) Hypoxanthine (II) in Deuterium Oxide (60 Mc).

investigators. ${ }^{4,5}$ Treatment of N-1-alkylinosine with alkali gave 5 -amino-1-( $\beta$-D-ribofuranosyl $)$

4) J. A. Montgomery and H. J. Thomas, J. Org. Chem., 28, 2304 (1963).

5) M. A. Stevens, H.W. Smith and G. B. Brown, J. Am. Chem. Soc., 81, 1734 (1959). imidazole-4-alkylcarboxamide. ${ }^{6)} \quad$ Bis-1, 9-( $\beta$-Dglucopyranosyl) hypoxanthine (I) and its 1,7isomer (II) were quite unstable in alkaline

6) E. Shaw, J. Am. Chem. Soc., 80, 3899 (1959); ibid., 81, 6021 (1959); ibid., 83, 4770 (1961). 


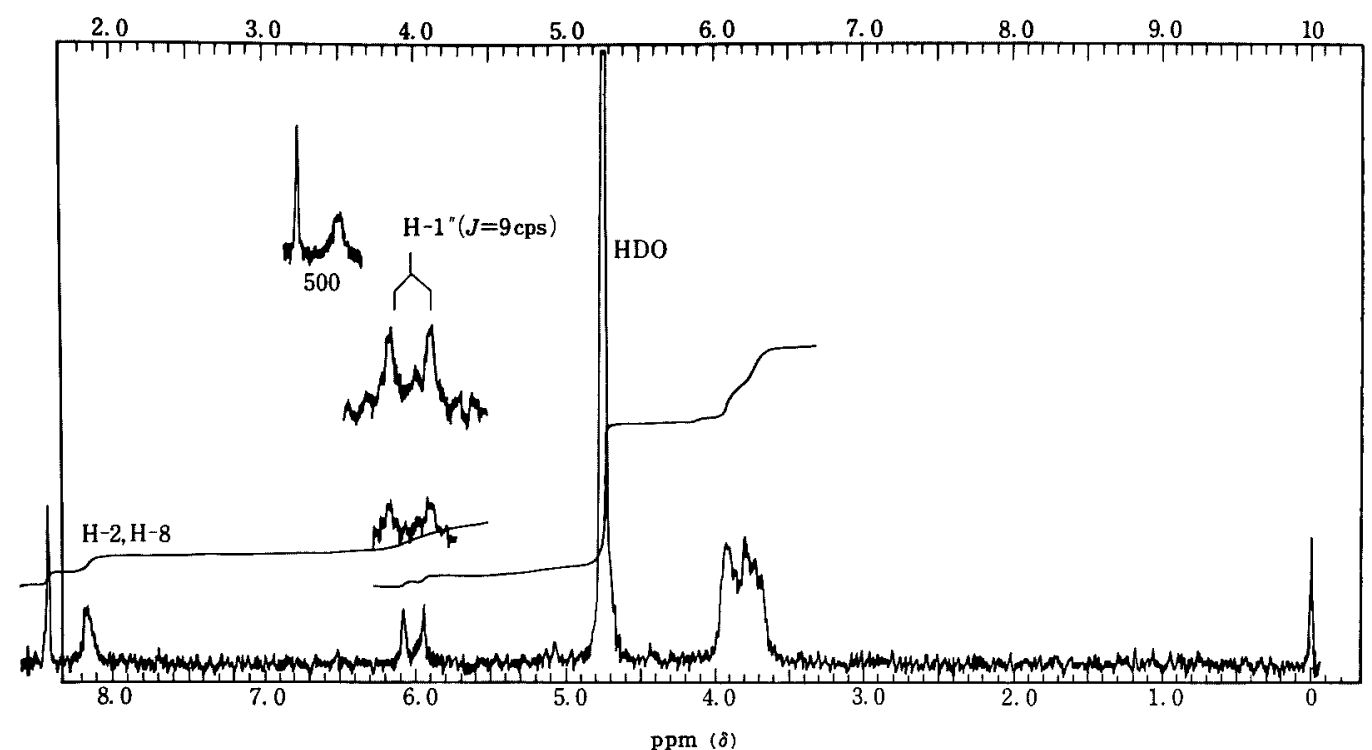

FIG. 3. NMR Spectrum of 1- $\beta$-D-Glucopyranosyl Hypoxanthine $(V)$ in Deuterium Oxide $(60 \mathrm{Mc})$.

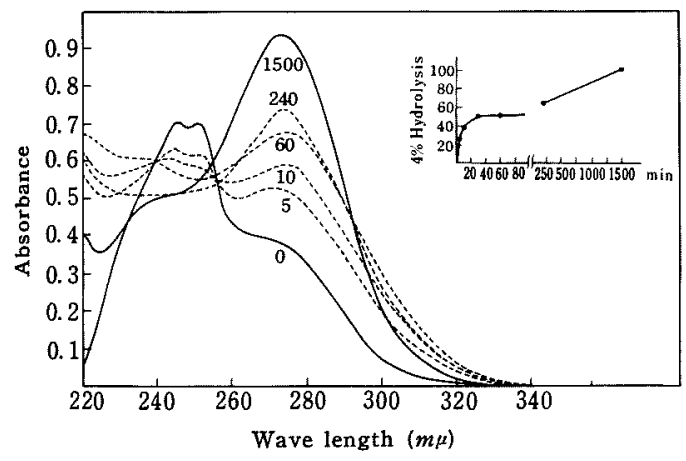

FIG. 4. Bis-1,9-( $\beta$-D-glucopyranosyl) hypoxanthine was dissolved in $0.05 \mathrm{~N}$ sodium hydroxide. The ultraviolet absorption pattern was immediately obtained with a Shimadzu recording spectrophotometer (solid line). Both blank cuvette and sample cuvette were set aside at room temperature. Absorption patterns were obtained after $5 \mathrm{~min}, 10$ $\mathrm{min}, 60 \mathrm{~min}, 240 \mathrm{~min}$ and $1500 \mathrm{~min}$. Percent hydrolysis was obtained spectrally.

solution. When they were stored in $0.05 \mathrm{~N}^{-}$ sodium hydroxide solution at room temperature, the absorption maximum of compound I shifted from $252 \mathrm{~m} \mu$ to $274 \mathrm{~m} \mu$ (Fig. 4), and that of compound II shifted from $256 \mathrm{~m} \mu$ to

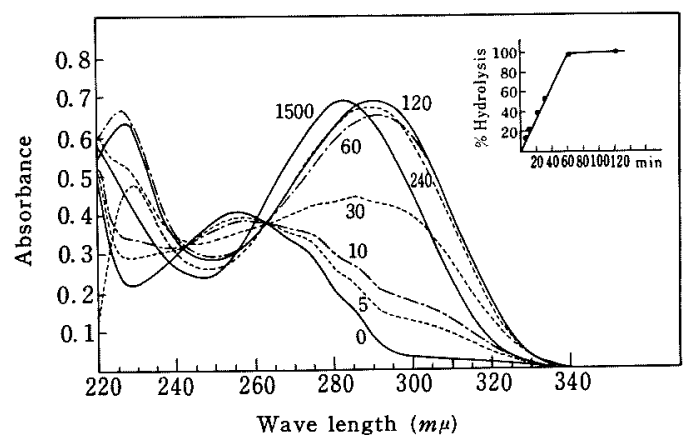

FIG. 5. The ultraviolet absorption patterns of bis$1,7-(\beta$-D-glucopyranosyl) hypoxanthine in $0.05 \mathrm{~N}$ sodium hydroxide were obtained after $0 \mathrm{~min}, 5$ min, $10 \mathrm{~min}, 30 \mathrm{~min}, 60 \mathrm{~min}$ (dotted and dashed line), $120 \mathrm{~min}$ (solid line), $240 \mathrm{~min}$ (dotted line) and $1500 \mathrm{~min}$ (solid line), as the same manner as described in FIg. 1. Percent hydrolysis was also obtained.

$291 \mathrm{~m} \mu$ (Fig. 5). By replacing the alkyl group of the pyrimidine ring nitrogen with glucosyl group, alkaline hydrolysis is expected to proceed more easily.

The above-mentioned chemical natures of the diglucosyl hypoxanthines, compound I and 
<smiles>[R]n1cnc2c(=O)[nH]cnc21</smiles><smiles>[R]n1c(C)nc2c(=O)[nH]cnc21</smiles><smiles>[R][R1]1cnc2c(ncn2[R])c1=O</smiles>

( IV")<smiles>[R]n1cnc2nc[nH]c(=O)c21</smiles><smiles>CCCCCCCC</smiles><smiles>[R]n1c(C)nc2ncn([B])c(=O)c21</smiles><smiles></smiles>

( II")

$\mathrm{R}=(2,3,4,6-$ tetra-O-acetyl $)-$ $\beta-\mathrm{D}$-glucopyranosy]

ChaRT 3<smiles>[R]n1cnc2c(nc(C)n2[R])c1=O</smiles>

(I)<smiles>[R]n1cnc2ncn([R])c2c1=O</smiles>

(II)<smiles>[R]NC(=O)c1nc([I-]C=O)n([R])c1N</smiles><smiles>[AlH2]</smiles><smiles>[R]NC(=O)c1c(N)nc([3H])n1[R]</smiles>

(II')

$\mathrm{R}=\beta-\mathrm{D}-\mathrm{glucopyranosyl}$

CHART 4

II, may provide strong additional evidence that one of the two glucosyl moieties in the respective compounds is linked to the pyrimidine nitrogen as described previously.

From the results obtained in the alkaline hydrolysis of $\mathrm{N}$-1-alkylinosine, ${ }^{6}$ compounds I and II were expected to give 5 -amino-1-( $\beta$-Dglucopyranosyl) imidazole-4-( $\beta$-D-glucopyranosyl) carboxamide $\left(I^{\prime}\right)$ and 5-amino-3- $(\beta-D-$ glucopyranosyl) imidazole-4-( $\beta$-D-glucopyranosyl) carboxamide $\left(\mathrm{II}^{\prime}\right)$, respectively, and this was actually confirmed by the following evidence. The products $\mathrm{I}^{\prime}$ and $\mathrm{II}^{\prime}$ obtained by alkaline hydrolysis possessed arylamino group, as detected by the Bratton-Marshall's diazotization reaction, ${ }^{7,8}$ and their infrared spectra revealed the presence of carboxamide $\mathrm{C}=\mathrm{O}$ stretching $\left(1620 \mathrm{~cm}^{-1}\right.$ and $1630 \mathrm{~cm}^{-1}$, re-

7) A.C. Bratton and E.K. Marshall, J. Biol. Chem., 128, 537 (1939).

8) J. Baddiley, J. G. Buchanan, F. E. Hardy and J. Stewart, J. Chem. Soc., 1959, 2892. 
spectively) (cf. the $\mathrm{C}=\mathrm{O}$ stretching of compounds I and II were $1690 \sim 1700 \mathrm{~cm}^{-1}$ ).

Since free glucose could not be detected in the reaction mixture by the Fehling reaction as well as by paper chromatography, $\mathrm{N}$ glucosylcarboxamide bonds in both compounds I' and II' were retained under such a condition as described above. Moreover, sodium formate, a by-product of this reaction, was detected by the reaction with mercuric chloride." Then, the acetylated compounds III and IV (III" and IV $^{\prime \prime}$ ) were reacted with mercuric bromide in an alkaline medium to obtain respective bromomercury derivatives. The ultraviolet absorption spectra of the bromomercury derivatives of III $^{\prime \prime}$ and $\mathrm{IV}^{\prime \prime}$ in aqueous ethanol revealed the patterns similar to those of acetylated compounds II and I $\left(\mathrm{II}^{\prime \prime}\right.$ and $\mathrm{I}^{\prime \prime}$ ), respectively (the details are shown in experimental). These derivatives were coupled with acetobromoglucose under the usual conditions of the Davoll-Lowy's method. ${ }^{10)}$ The coupling product (23.3\% Yield) obtained from III $^{\prime \prime}$ was identical with compound $\mathrm{II}^{\prime \prime}$, and the product (17\% Yield) from IV $^{\prime \prime}$ was identical with $\mathrm{I}^{\prime \prime}$ Thus, the allocations of bromomercury moieties to the position 1 of hypoxanthine in the bromomercury derivatives of acetylated compounds III and IV (III" and IV" ${ }^{\prime \prime}$ ) were reasonably suggested. ${ }^{11 \prime}$

The result indicates that the attachment of mercury to hypoxanthine would be at least the $(\mathrm{N}-1)-(\mathrm{O}-6)$ grouping, besides the known $\mathrm{N}-7$ or $\mathrm{N}-9 .{ }^{11}$

It is then assumed that the bromomercury derivative of hypoxanthine obtained under the above-mentioned conditions would be a mixture of mono- (1:1) and di- (2:1) bromomercury hypoxanthines ${ }^{1 /}$ and that the incoming acetobromoglucose attacks the nitrogen bearing the

9) F. Feigl, "Spot tests in Organic Analysis", Elsevier Publishing Company, Amsterdam, 1956, p. 341 .

10) J. Davoll and B. A. Lowy, J. Am. Chem. Soc., 73, 1650 (1951).

i1) J. A. Montgomery and H. J. Thomas, J. Org. Chem., 31, 1411 (1966). mercury of the bromomercury groups to displace the metal group. If the assumption is true, it is expected that the mono- (1:1) bromomercury hypoxanthine reacts with one more equivalent of mercuric bromide in alkaline medium, and that the obtained di- $(2: 1)$ bromomercury hypoxanthine requires one more equivalent of acetobromoglucose to be coupled to give diglucosides. In fact, this was confirmed by the following experiment.

Monobromomercury hypoxanthine was reacted with mercuric bromide in $1_{N}$ sodium hydroxide and the obtained (2:1) derivative was refluxed with two molar equivalents of acetobromoglucose. The ratio of the yield of diglucosides against that of monoglucoside was increased by 2.5 times.

\section{EXPERIMENTAL}

Methods. The melting points were determined on a Yanagimoto micromelting point apparatus, and corrected. The ultraviolet spectra were measured with a Model-139 Hitachi Perkin-Elmer spectrophotometer, and the infrared spectra were measured with a model AR-275 Shimadzu spectrophotometer using potassium bromide disks unless otherwise stated. The NMR spectra were recorded on a Varian A-60 spectrophotometer in $\mathrm{CDCl}_{3}$ and $\mathrm{D}_{2} \mathrm{O}$ solvents using tetramethylsilane and D.S.S. as reference compounds. The $[\alpha]_{D}$ values were determined with a Rex photoelectric polarimeter and the ORD curves were measured with a JASCO automatic recording spectropolarimeter. The $R f$ values were obtained by descendtng chromatography on Whatman No. 1 paper with the solvent systems, pyridine: butanol: water $=1: 1: 1 \mathrm{v} / \mathrm{v}$ (solventA), butanol: acetic acid: water $=12: 3: 5 \mathrm{v} / \mathrm{v}$ (solvent-B) and isobutyric acid: water: ammonium hydroxide $(d$, 0.88):0.I M-versene $=100: 55.8: 4.2: 1.6 \mathrm{v} / \mathrm{v}$ (solvent-C).

Bromomercury hypoxanthine. To a hot solution of $6.0 \mathrm{~g}$ ( $46 \mathrm{mmoles}$ ) of hypoxanthine in $250 \mathrm{ml}$ of water containing $1.8 \mathrm{~g}$ ( $46 \mathrm{mmoles)}$ of sodium hydroxide was added with stirring $16.5 \mathrm{~g}$ ( 46 mmoles) of mercuric bromide in hot alcohol. Precipitate formed immediately and the resulting suspension was stirred at room temperature for $45 \mathrm{~min}$ and then chilled. The precipitate was collected by centrifugation. It was washed with deionized water until free from bromide ion and then with ethanol and ether. It was dried for $24 \mathrm{hr}$ at $110^{\circ} \mathrm{C}(2 \mathrm{mmHg})$ over phosphoric 
anhyride, yield $15.18 \mathrm{~g}(83 \%)$. Anal. Found: N, 13.75 Calcd. for $\mathrm{C}_{5} \mathrm{H}_{3} \mathrm{ON}_{4} \mathrm{HgBr}$ : N, $13.48 \%$.

Bis-1, 9 -( $2^{\prime}, 3^{\prime}, 4^{\prime}, 6^{\prime}$-tetra-0-acetyl $)$ - $\beta$-D-glucopyra-

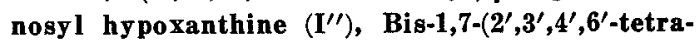
0 -acetyl)- $\boldsymbol{\beta}$-D-glucopyranosyl hypoxanthine (II"), $\left(2^{\prime}, 3^{\prime}, 4^{\prime}, 6^{\prime}\right.$-Tetra-0-acety 1$)-7-\beta$-D-glucopyranosyl hypoxanthine $\left(I \mathrm{II}^{\prime \prime}\right)$ and $\left(2^{\prime}, 3^{\prime}, 4^{\prime}, 6^{\prime}\right.$-Tetra-0-acetyl $)-9$ $\beta$-D-glucopyranosyl hypoxanthine $\left(I^{\prime \prime}\right)$. The finely ground mixture of $7.0 \mathrm{~g}$ (17.0 mmoles) of bromomercury hypoxanthine and $7.0 \mathrm{~g}$ of Celite No. 545 was previously dried for $24 \mathrm{hr}$ at $110^{\circ} \mathrm{C}(2 \mathrm{~mm}-\mathrm{Hg})$ over phosphoric anhydride and suspended in $300 \mathrm{ml}$ of dry xylene. The suspension was subjected to azeotropical distillation and cooled to room temperature. To the resulting suspension was added at once $6.9 \mathrm{~g}$ (16.8 mmoles) of acetobromoglucose dissolved in dry xylene (ca. $90 \mathrm{ml}$ ). The mixture was heated for $2 \mathrm{hr}$ under reflux with stirring and then filtered. The filter cake was washed with hot chloroform (three $100 \mathrm{ml}$-portions). The hot xylene filtrate was evaporated to dryness in vacuo at below $40^{\circ} \mathrm{C}$, and the residue was dissolved in $100 \mathrm{ml}$ of warm chloroform and this was combined with the chloroform washings. The combined solution was washed with $30 \%$ potassium iodide solution (two $100 \mathrm{ml}$-portions) and with water (two $100 \mathrm{ml}$-portions), dried with magnesium sulfate and evaporated to dryness in vacuo. Crude coupling product $(6.8 \mathrm{~g})$ was obtained as a glass.

The t.l.c. on alumina* in ethylacetate-methanol (20:1) showed four zones under an UV-lamp and with vanadic acid-sulfuric acid spray at the following $R f$ values: compound $\mathrm{I}^{\prime \prime}, 0.90$; compound $\mathrm{II}^{\prime \prime}, 0.83$; compound III", 0.20; compound IV", 0.02. The crude product was acetylated with pyridine-acetic anhydride in the usual manner and chromatographed on a column packed with $150 \mathrm{~g}$ of neutralized alumina.* Elution with $650 \mathrm{ml}$ of ethylacetate removed $4.2 \mathrm{~g}$ of the first fraction (fully acetylated glucose, compound $\mathrm{I}^{\prime \prime}$ and compound $\left.\mathrm{II}^{\prime \prime}\right)$. Further elution with about $800 \mathrm{ml}$ of ethylacetate-methanol (3:1) removed $1.5 \mathrm{~g}$ of another fraction (compound II" and compound $\mathrm{I}^{\prime \prime}$ ). The former fraction was concentrated and chromatographed again on a column packed with $150 \mathrm{~g}$ of silicic acid.** Elution with $88 \mathrm{ml}$ of ethylacetate-chloroform (3:1) removed $0.7 \mathrm{~g}$ of fully acetylated glucose and successive elution with $110 \mathrm{ml}$ of the same solvent removed $1.8 \mathrm{~g}$

* Purchased from E. Merck AG, Darmstadt. ** Purchased from Mallinkrodt, New York, U.S.A. of compound I' $(R f 0.90)$. Further $40 \mathrm{ml}$ of the eluate was set aside and elution with about 1 liter of ethylacetate removed $1.7 \mathrm{~g}$ of compound $\mathrm{II}^{\prime \prime}(R f$ 0.83). Each fractionated material was dissolved in $100 \mathrm{ml}$ of chloroform and washed with water. Evaporation of the dried chloroform solution in vacuo gave $1.70 \mathrm{~g}(12.7 \%)$ of compound $\mathrm{I}^{\prime \prime}$ as a glass, and $1.64 \mathrm{~g}$ $(12.3 \%)$ of compound $\mathrm{II}^{\prime \prime}$ as a glass. Both products were crystallized from ethanol.

Compound $I^{\prime \prime} \operatorname{mp~} 139.5 \sim 141.0^{\circ} \mathrm{C} \lambda_{\max }^{\text {EtoH }} \mathrm{m} \mu(\varepsilon): 243$ (9300), $250(8700), 271(4700) . \quad \lambda_{\min }^{\mathrm{EtOH}} \mathrm{m} \mu(\varepsilon): 224(4100)$, 248 (8400), 261 (5300). Anal. Found: N, 7.20***. Calcd. for $\mathrm{C}_{33} \mathrm{H}_{40} \mathrm{O}_{19} \mathrm{~N}_{4}: \mathrm{N}, 7.03 \%$.

Compound II' $\operatorname{mp} 150.5 \sim 152.0^{\circ} \mathrm{C} \lambda_{\max }^{\mathrm{EtOH}} \mathrm{m} \mu(\varepsilon): 255$ (5500), $247(\mathrm{sh}), 265(\mathrm{sh}) . \quad \lambda_{\min }^{\mathrm{EtOH}} \mathrm{m} \mu(\varepsilon): 233(4000)$. Anal. Found: N, 6.71***. Calcd. for $\mathrm{C}_{33} \mathrm{H}_{40} \mathrm{O}_{19} \mathrm{~N}_{4}: \mathrm{N}$, $7.03 \%$.

The latter fraction of the alumina column chromatography was concentrated and chromatographed again on a column packed with $150 \mathrm{~g}$ of neutralized alumina. Elution with $120 \mathrm{ml}$ of ethylacetate-chloroform-methanol $(4: 1: 2)$ removed $190 \mathrm{mg}$ of the impurities and next $120 \mathrm{ml}$ of eluation removed $520 \mathrm{mg}$ of compound III" $(R f 0.20)$. Further elution with $500 \mathrm{ml}$ of the same solvent and $900 \mathrm{ml}$ of ethylacetate-ethanol (1:1) removed $910 \mathrm{mg}$ of compound IV" (Rf 0.02). These fractionated materials were dissolved in $200 \mathrm{ml}$ of chloroform and washed with two $20 \mathrm{ml}$-portions of water. Evaporation of the dried chloroform solution in vacuo gave $470 \mathrm{mg}(6.0 \%)$ of compound III" and $800 \mathrm{mg}(10.2 \%)$ of compound IV". Compound III" and IV" were crystallized from ethanol and from ethyl-acetate, respectively. Both compounds were recrystallized from ethanol.

Compound III" $\mathrm{mp} 243.5 \sim 245.0^{\circ} \mathrm{C} \lambda_{\max }^{\mathrm{EtOH}} \mathrm{m} \mu(\varepsilon): 252$ $(10,200) . \quad \lambda_{\text {min }}^{\mathrm{EtOH}} \mathrm{m} \mu(\varepsilon): 217(6200) .[\alpha]_{\mathrm{D}}^{22}-4.4^{\circ}(c=1.28$, $\mathrm{CHCl}_{3}$ ). Anal. Found: $\mathrm{C}, 48.82 ; \mathrm{H}, 4.83 ; \mathrm{N}, 12.20$. Calcd. for $\mathrm{C}_{19} \mathrm{H}_{22} \mathrm{O}_{10} \mathrm{~N}_{4}$ : C, 48.93; $\mathrm{H}, 4.75 ; \mathrm{N}, 12.01 \%$.

Compound IV" $\mathrm{mp} 266.0 \sim 267.0^{\circ} \mathrm{C} \lambda_{\mathrm{max}}^{\mathrm{EtOH}} \mathrm{m} \mu(\varepsilon): 244$ $(11,000) . \quad \lambda_{\min }^{\mathrm{EtOH}} \mathrm{m} \mu(\varepsilon): 217(4200) . \quad[\alpha]_{\mathrm{D}}^{22}-26.2^{\circ} \quad(c=$ 1.54, $\mathrm{CHCl}_{3}$ ). Anal. Found: C, 48.94; H, 4.76; N, 12.01. Calcd. for $\mathrm{C}_{19} \mathrm{H}_{22} \mathrm{O}_{10} \mathrm{~N}_{4}$ : $\mathrm{C}, 48.93 ; \mathrm{H}, 4.75 ; \mathrm{N}$, $12.01 \%$.

Bis-1,9-( $\beta$-D-glucopyranosyl) hypoxanthine (I). One $\mathrm{g}$ of compound $\mathrm{I}^{\prime \prime}$ was dissolved in $80 \mathrm{ml}$ of methanolic ammonia saturated at $0^{\circ} \mathrm{C}$. The reaction mixture was stored overnight in an ice-box $\left(5^{\circ} \mathrm{C}\right)$. After evaporation of the solvent the residue was dissolved

*** Microanalysis of $\mathrm{C}$ and $\mathrm{H}$ was not performed. 
in $10 \mathrm{ml}$ of water and washed with chloroform. The aqueous layer was evaporated to dryness. The residue was treated with boiling ethanol and chilled. Amorphous powder was obtained by filtration. It was recrystallized three times from ethanol and dried over phosphoric anhydride at $110^{\circ} \mathrm{C}(2 \mathrm{mmHg})$ overnight: Yield, $423 \mathrm{mg}(73.0 \%), \mathrm{mp}, 215.5 \sim 216.5^{\circ} \mathrm{C} ; \lambda_{\max }^{0.05 \mathrm{~N} \mathrm{HCl}}$ $\mathrm{m} \mu(\varepsilon): 251(9600), \lambda_{\max }^{\mathrm{H}_{2} \mathrm{O}, \mathrm{pH}} \mathrm{m} \mu(\varepsilon): 251(9500), \lambda_{\max }^{0.05 \mathrm{~N}} \mathrm{NaOH}$ $\mathrm{m} \mu: 252 ;[\alpha]_{\mathrm{D}}^{25}+15.0^{\circ}\left(c=2.2, \mathrm{H}_{2} \mathrm{O}\right) ; R f$ value 0.13 (solvent-B), 0.38 (solvent-C). The ORD curve was positive plain in the range of $350 \mathrm{~m} \mu$ to $700 \mathrm{~m} \mu$.

Anal. Found: D, 43.47; H, 5.66; N, 11.81. Calcd. for $\mathrm{C}_{17} \mathrm{H}_{24} \mathrm{O}_{11} \mathrm{~N}_{4} \cdot \frac{1}{2} \mathrm{H}_{2} \mathrm{O}$ : C, 43.49; $\mathrm{H}, 5.37 ; \mathrm{N}, 11.93 \%$.

Bis-1,7-( $\beta$-D-glucopyranosyl) hypoxanthine (II). Similarly, $910 \mathrm{mg}$ of compound $\mathrm{II}^{\prime \prime}$ was deacetylated, affording $376 \mathrm{mg}(71.2 \%)$ of the titled compound. $\mathrm{mp}, 221.5 \sim 223.0^{\circ} \mathrm{C}$ (sintered at $212^{\circ}$ ); $\lambda_{\max }^{0.05 \mathrm{~N} \mathrm{HCl}} \mathrm{m} \mu(\varepsilon)$ : $254(7000), \lambda_{\max }^{\mathrm{H}_{2} \mathrm{O}, \mathrm{pH} 6} \mathrm{~m} \mu(\varepsilon): 256(6200), \lambda_{\max }^{0.05 \mathrm{~N} \mathrm{NaOH}} \mathrm{m} \mu$ : $256 ;[\alpha]_{\mathrm{D}}^{25}+20.0^{\circ}\left(c=2.07, \mathrm{H}_{2} \mathrm{O}\right) ; R f$ value 0.15 (solventB), 0.40 (solvent-C). The ORD curve was positive plain in the range of $350 \mathrm{~m} \mu$ to $700 \mathrm{~m} \mu$. Anal. Found: C, 43.21; H, 5.63; N, 11.62. Calcd. for $\mathrm{C}_{17} \mathrm{H}_{24} \mathrm{O}_{11} \mathrm{~N}_{4}$. ${ }_{2} \mathrm{H}_{2} \mathrm{O}: \mathrm{C}, 43.49 ; \mathrm{H}, 5.37 ; \mathrm{N}, 11.93$.

7- $\beta$-D-Glucopyranosyl hypoxanthine (III). Deacetylation of $525 \mathrm{mg}$ of compound III' $^{\prime \prime}$ in $25 \mathrm{ml}$ of methanolic ammonia afforded $250 \mathrm{mg}(74.4 \%)$ of compound III, mp, $200.5 \sim 203.5^{\circ} \mathrm{C}$. The compound was first crystallized from $50 \%$ ethanol, recrystallized from water and dried over phosphoric anhydride at $110^{\circ} \mathrm{C}$ ( $2 \mathrm{mmHg}$ ) overnight. mp, $203.5 \sim 205.0^{\circ} \mathrm{C} ; \lambda_{\max }^{0.05 \mathrm{~N} \mathrm{HCl}}$ $\mathrm{m} \mu(\varepsilon): 253.5(9000), \lambda_{\max }^{\mathrm{H}_{2} \mathrm{O}, \mathrm{pH}} \mathrm{m} \mu(\varepsilon): 252(8800), \lambda_{\max }^{0.05 \mathrm{NaOH}}$ $\mathrm{m} \mu(\varepsilon): 263(9200) ;[\alpha]_{\mathrm{D}}^{16}-48.0^{\circ}(c=1.17,1 \mathrm{~N} \mathrm{NaOH})$, $[\alpha]_{\mathrm{D}}^{33}+8.7^{\circ}\left(c=1.5, \mathrm{H}_{2} \mathrm{O}\right) ; \quad R f$ value 0.61 (solvent- $\mathrm{A}$ ), 0.19 (solvent-B), 0.52 (solvent-C). The ORD curve was negative plain in the range of $350 \mathrm{~m} \mu$ to $700 \mathrm{~m} \mu$. Anal. Found: C, 41.89; H, 5.31; N, 17.82. Calcd. for $\mathrm{C}_{11} \mathrm{H}_{14} \mathrm{O}_{6} \mathrm{~N}_{4} \cdot \mathrm{H}_{2} \mathrm{O}: \mathrm{C}, 41.77 ; \mathrm{H}, 5.10 ; \mathrm{N}, 17.72 \%$.

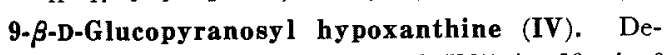
acetylation of $1.0 \mathrm{~g}$ of compound $\mathrm{IV}^{\prime \prime}$ in $50 \mathrm{ml}$ of methanolic ammonia afforded $560 \mathrm{mg}(80.7 \%)$ of compound IV. It was recrystallized from water and dried over phosphoric anhydride overnight $(2 \mathrm{mmHg}) . \mathrm{mp}$, $275.0 \sim 276.0^{\circ} \mathrm{C}$ (dec), $\lambda_{\max }^{0.05 \mathrm{~N} \mathrm{HCl}} \mathrm{m} \mu(\varepsilon): 249(11,000)$, $\lambda_{\text {. }}^{\mathrm{H}_{2} \mathrm{O}, \mathrm{pH}} \mathrm{m} \mu(\varepsilon): \quad 248(\mathrm{I} 4,800), \quad \lambda_{\max }^{0.05 \mathrm{~N} N \mathrm{OH}} \mathrm{m} \mu(\varepsilon): 254$ $(12,900) ;[\alpha]_{\mathrm{D}}^{22}-38.4^{\circ}(c=2.11,1 \mathrm{~N} \mathrm{NaOH}),[\alpha]_{\mathrm{D}}^{31}-2.1^{\circ}$ $\left(c=0.9, \mathrm{H}_{2} \mathrm{O}\right.$ ); $R f$ value 0.60 (solvent-A), 0.16 (solventB), 0.47 (solvent-C). Anal. Found: C, 41.79; H, 5.08; $\mathrm{N}$, 17.84. Calcd. for $\mathrm{C}_{11} \mathrm{H}_{14} \mathrm{O}_{6} \mathrm{~N}_{4} \cdot \mathrm{H}_{2} \mathrm{O}: \mathrm{C}, 41.77 ; \mathrm{H}$, $5.10 ; \mathrm{N}, 17.72 \%$.
1- $\beta$-D-Glucopyranosyl hypoxanthine (V) from Bis-1,9-( $\beta$-D-glucopyranosyl) hypoxanthine $(I)$ and Bis-1,7-( $\beta$-D-glucopyranosyl) hypoxanthine (II). Fifty $\mathrm{mg}$ of compound I was dissolved in $5 \mathrm{ml}$ of $1 \mathrm{~N}$ hydrochloric acid and heated on a steam bath for $1.5 \mathrm{hr}$. The reaction mixture was evaporated to dryness with several additions of methanol in vacuo at below $40^{\circ} \mathrm{C}$. The residue was triturated with methanol and filtered. The collected white powder was dissolved in minimum amount of boiling water and neutralized with dilute ammonium hydroxide and chilled.

Colorless crystals were deposited and filtered. Yield, $16 \mathrm{mg}(49.4 \%), \mathrm{mp}, 273.5 \sim 275.0^{\circ} \mathrm{C}$ (dec). It was recrystallized from water for analysis. $\lambda_{\max }^{0.05 \mathrm{~N} \mathrm{HCl}} \mathrm{m} \mu(\varepsilon)$ : $249(9400), \quad \lambda_{\max }^{\mathrm{H}_{2} \mathrm{O}, \mathrm{pH} 6} \mathrm{~m} \mu(\varepsilon): 250.5(8800), \lambda_{\max }^{0.05 \mathrm{~N} \mathrm{NOH}}$ $\mathrm{m} \mu(\varepsilon): 260.5(9300) ;[\alpha]_{D}^{31.0}+16.2^{\circ}\left(c=0.88, \mathrm{H}_{2} \mathrm{O}\right) ; R f$ value 0.60 (solvent-A) Anal. Found: C, 43.99; H, 4.91; $\mathrm{N}$, 18.34. Calcd. for $\mathrm{C}_{11} \mathrm{H}_{14} \mathrm{O}_{6} \mathrm{~N}_{4}: \mathrm{C}, 44.29 ; \mathrm{H}, 4.72$; $\mathrm{N}, 18.79 \%$.

Fifty $\mathrm{mg}$ of compound II was hydrolyzed with acid in the manner described above to give $10 \mathrm{mg}(31.0 \%)$ of compound $\mathrm{V}$.

Bis-1,9-( $\beta$-D-glucopyranosyl) hypoxanthine (I) from $\left(2^{\prime}, 3^{\prime}, 4^{\prime}, 6^{\prime}\right.$-Tetra-0-acetyl $)$-9- $\beta$-D-glucopyranosyl hypoxanthine $\left(\mathrm{IV}^{\prime \prime}\right)$.

a) Bromomercury derivative of compound IV". Three hundred and twenty $\mathrm{mg}$ of compound IV" was dissolved in $15 \mathrm{ml}$ of boiling deionized water containing $250 \mathrm{mg}$ ( $0.69 \mathrm{mmole}$ ) of mercuric bromide, and $0.69 \mathrm{ml}$ of $1 \mathrm{~N}$ sodium hydroxide solution was grudually added into this reaction mixture. The solution was heated on a steam bath for $1.5 \mathrm{hr}$ and stored overnight in an ice box. The precipitate was filtered and washed with a small amount of cold water. Yield, $227 \mathrm{mg}(44.3 \%)$, $\mathrm{mp} 191.0 \sim 192.5^{\circ} \mathrm{C} . \lambda_{\max }^{50 \% \mathrm{EtOH}}$ $\mathrm{m} \mu: 248,250, \lambda_{\mathrm{min}}^{50 \% \mathrm{EtOH}} \mathrm{m} \mu: 224$. cf. Compound $I^{\prime \prime}$ $\lambda_{\max }^{50 \% \mathrm{EtOH}} \mathrm{m} \mu: 245,251, \lambda_{\mathrm{min}}^{50 \% \mathrm{EtOH}} \mathrm{m} \mu: 226$.

b) Bis-1,9-( $\beta$-D-glucopyranosyl) hypoxanthine (I). Two hundred and twenty five mg of the bromomercury derivative of compound IV'" was dried for $24 \mathrm{hr}$ at $110^{\circ} \mathrm{C}(2 \mathrm{mmHg})$ over phosphoric anhydride and suspended in $10 \mathrm{ml}$ of dry xylene. One hundred and twenty $\mathrm{mg}$ of acetobromoglucose was added to the suspension and refluxed for $1 \mathrm{hr}$. The insoluble material was removed and identified as compound IV". The xylene solution was concentrated in vacuo and the residue was dissolved in chloroform. The solution was washed with water, dried with magnesi- 
um sulfate and evaporated. The oily product was chromatographed on $\mathrm{a} 20 \mathrm{~g}$ of silicic acid column under the same condition as mentioned previously, and $40 \mathrm{mg}$ of compound $\mathrm{I}^{\prime \prime}(17 \%)$ was obtained. Deacetylation of this compound by methanolic ammonia gave $14 \mathrm{mg}$ of compound I which was identical with an authentic sample in every respect examined.

Bis-1,7-( $\beta$-D-glucopyranosyl) hypoxanthine (II) from $\left(2^{\prime}, 3^{\prime}, 4^{\prime}, 6^{\prime}\right.$-Tetra-0-acety $)$-7- $\beta$-D-glucopyranosyl) hypoxanthine (III').

a) Bromomercury derivative of compound III" $^{\prime \prime}$. Two hundred and eighty four $\mathrm{mg}$ (55.5\% yield) of the bromomercury derivative of compound III" was obtained from $320 \mathrm{mg}$ of compound $\mathrm{III}^{\prime \prime}$ in the same manner as described above. $\mathrm{mp}, 189 \sim 191.0^{\circ} \mathrm{C}$, $\lambda_{\max }^{50 \% \mathrm{EtOH}} \mathrm{m} \mu: 251 \sim 253, \lambda_{\min }^{50 \% \mathrm{EtOH}} \mathrm{m} \mu: 233$. cf. compound $\mathrm{I}^{\prime \prime}, \lambda_{\max }^{50 \% \mathrm{EtOH}} \mathrm{m} \mu: 254, \lambda_{\mathrm{min}}^{50 \% \mathrm{ElOH}} \mathrm{m} \mu: 232$.

b) Bis-1,7-( $\beta$-D-glucopyranosyl) hypoxanthine (II). Two hundred and eighty $\mathrm{mg}$ of the bromomercury derivative of compound III" $^{\prime \prime}$ was reacted with $130 \mathrm{mg}$ of acetobromoglucose in $10 \mathrm{ml}$ of xylene and $70 \mathrm{mg}$ ( $23.3 \%$ yield) of compound $\mathrm{II}^{\prime \prime}$ was obtained by column chromatography ( $30 \mathrm{~g}$ of silicic acid). Deacetylation by methanolic ammonia gave $20 \mathrm{mg}$ of II" which was identical with an authentic sample in every respect examined.

Bis-bromomercury hypoxanthine. Bromomercury hypoxanthine $(5.3 \mathrm{~g}, 13.0 \mathrm{mmoles})$ and Celite $545(2.1 \mathrm{~g})$ were suspended in $13.0 \mathrm{ml}$ of $1 \mathrm{~N}$ sodium hydroxide, and $4.7 \mathrm{~g}$ (13.0 mmoles) of mercuric bromide in hot alcohol was added to the suspension. The reaction mixture was refluxed with stirring for $1 \mathrm{hr}$ and stored in an ice-box overnight and filtered. The filter cake (pale red-brown solid) was washed well with deionized water and with alcohol, and then dried over phosphoric anhydride overnight. Yield, $9.2 \mathrm{g*}$ (80.0\%, calcd. as bis-bromomercury derivative of hypoxan- thine). Anal. Found: N, 8.06. Calcd. for $\mathrm{C}_{5} \mathrm{H}_{2} \mathrm{ON}_{4}-$ $\mathrm{Hg}_{2} \mathrm{Br}_{2}: \mathrm{N}, 7.83 \%$.

Glucosidation of bis-bromomercury hypoxanthine with two equimolar amount of acetobromoglucose. The bis-bromomercury derivative of hypoxanthine $(7.0 \mathrm{~g}, 10.2 \mathrm{mmoles})$ and Celite $(2.1 \mathrm{~g}) 545$ were suspended in $100 \mathrm{ml}$ of xylene and the suspension was subjected to azeotropical distillation $(60 \mathrm{ml})$. Then, $8.36 \mathrm{~g}$ ( $10.2 \mathrm{mmoles})$ of acetobromoglucose was added. The mixture was refluxed for $2 \mathrm{hr}$ with vigorous stirring. After $10 \mathrm{~min}$ the red color due to the bis-bromomercury derivative of hypoxanthine turned to pale yellow. The reaction mixture was filtered while warm and the filter cake was washed with chloroform $(400 \mathrm{ml})$. The filtrate was evaporated in vacuo and dissolved in $600 \mathrm{ml}$ of chloroform. The chloroform washings and the solution obtained were combined and washed with $30 \%$ potassium iodide (two $160 \mathrm{ml}$-portions) and water (two $200 \mathrm{ml}$-portions) to give $10.2 \mathrm{~g}$ of an oily product. This oily product was subjected to column chromatography in the same manner as described above. The yields of four products were: compound $\mathrm{I}^{\prime \prime} 2.46 \mathrm{~g}$ (15.2\%), compound II' $1.86 \mathrm{~g}(11.5 \%)$, compound III' $280 \mathrm{mg}(2.9 \%)$, compound IV" $400 \mathrm{mg}$ ( $4.2 \%$ ).

Acknowledgement. The authors wish to thank Professor T. Mitsui for performing microanalyses and to Professor M. Nakajima and his associates for measuring infrared spectra.

Thanks are also due to Dr. T. Shinguh for the measurement of NMR spectra.

* This yield includes $2.1 \mathrm{~g}$ of Celite; therefore, the yield of pure product was $7.1 \mathrm{~g}$. For preparation of the analytical sample of the bis-bromomercury hypoxanthine, the Celite was not added in a small run. 